\title{
Crystal Structure of $\boldsymbol{\beta}$ Poly(L-valine)
}

\author{
Osamu YAMASHITA* and Tamaichi ASHIDA \\ Department of Applied Chemistry, Faculty of Engineering, \\ Nagoya University, Chikusa, Nagoya 464, Japan
}

(Received September 6, 1983)

\begin{abstract}
Poly(L-valine) gave an excellent fiber photograph, and its crystal and molecular structures were determined on the basis of $72 \mathrm{X}$-ray intensity data. A molecular structure was constructed using the equations for helical parameters as functions of empirical internal coordinates. The crystal structure was refined by the $R$-value-map and least-squares methods with three parameters defining the packing scheme of the molecules. The crystal data: $\mathrm{P} 2{ }_{1} 2_{1} 2_{1}, a=4.80, b=$ $19.14, c=6.59 \AA$. The final $R$ value was 0.192 . The crystal structure is fundamentally the same $\beta$ pleated sheet as that of poly(L-alanine). However, the molecule shows a considerable contraction (about $14 \%$ ) along the fiber axis owing to the presence of a bulky isopropyl side chain.

KEY WORDS Poly(L-valine) / $\beta$ Pleated Sheet / X-Ray Diffraction /
\end{abstract}

In our previous paper, ${ }^{1}$ a preliminary crystallographic study of several poly $(\alpha$-amino acid)s having hydrophobic side chains, such as poly(Lvaline), poly(L-isoleucine), and poly(L-phenylalanine), was reported. Among these, poly(L-valine) was shown to exist in an antiparallel $\beta$-sheet structure as well as in an $\alpha$-helix, although the crystallinity of the latter was fairly low; poly(L-isoleucine) crystallized in an antiparallel $\beta$-sheet; and poly(L-phenylalanine) suggested co-existence of both $\omega$ - and $\alpha$-helices.

Among many other poly( $\alpha$-amino acid)s the structures could be studied in detail by the $\mathrm{X}$-ray method only for $\alpha$-helix and $\beta$-pleated sheet poly $(\mathrm{L}-$ alanine) ${ }^{2,3}$ Poly(L-proline $)^{4}$ and polyglycine ${ }^{5}$ gave only poor powder patterns. Although poly $(\gamma-$ benzyl L-glutamate) ${ }^{6}$ gave a well developed fiber pattern, its detailed structural parameters are not yet known. $\beta$ Poly(L-valine) gave a well-oriented fiber specimen and an X-ray pattern of good quality, as reported in the previous paper. ${ }^{1}$ Based on this X-ray pattern, a precise structural study was carried out, and the results are described in this report.

Hydrophobic cores play key roles in folding globular proteins into active tertiary structures.
Often, hydrophobic interactions among side chains play a very important part in making quarternary structures of protein molecules or subunits. Thus, a study of the structural features of bulky hydrophobic side chains is important both chemically and biologically.

\section{MATERIALS AND METHOD}

The oriented fiber specimen of $\beta$ poly(L-valine) was the same as that used in the previous study. ${ }^{1} \mathrm{X}$ Ray diffraction fiber photographs were taken with an evacuated cylindrical camera in diameter $70 \mathrm{~mm}$. The fiber axis of the specimen was set parallel to the cylindrical axis, and two sheets of film were mounted in a film cassette at the same time. Intensity data were derived by allowing all the optical density profiles of the diffraction photographs to be processed by an OPTRONICS P-1000 drum scanner. The absorption correction was made for the oblique incidence of the X-ray on the outer film, and the background densities estimated as the minimum value within the arc having the same diffraction angle were subtracted. Diffraction spots were indexed and the intensities were integrated. Merging the intensity data of several films and scaling them

* Present address: Kao Corporation, Tochigi Research Laboratories, 2606, Akabane, Ichikai-machi, Haga, Tochigi 321-34, Japan. 
Table I. Crystal data

\begin{tabular}{ll} 
Formula weight of residue & $M=99.13\left(\mathrm{C}_{5} \mathrm{H}_{9} \mathrm{ON}\right)_{n}$ \\
Space group & $\mathrm{P} 2{ }_{1} 2_{1} 2_{1}$ \\
Unit cell dimensions & $a=4.80 \AA$ \\
& $b=19.14 \AA$ \\
& $c=6.59 \AA$ \\
Calculated density & $D_{\mathrm{x}}=1.09 \mathrm{gcm}^{-3}$ \\
Measured density & $D_{\mathrm{m}}=1.18 \mathrm{gcm}^{-3}$ \\
Number of residues & $Z=4$ \\
in the unit cell & \\
\hline
\end{tabular}

with each other, we obtained intensity data of 27 resolved spots involving 72 independent reflections. Lorentz and polarization corrections were made using the method of Arnott. ${ }^{7}$ The crystallographic data adopted in this study were reported previously (Table I). ${ }^{1}$

\section{STRUCTURE DETERMINATION}

\section{Molecular Structure}

For a peptide helix, $\left(-\mathrm{NH}-\mathrm{C}^{\alpha} \mathrm{HR}-\mathrm{C}^{\prime} \mathrm{O}\right)_{n}$, the helical parameters $t$ (unit twist) and $h$ (unit height) were expressed by Miyazawa ${ }^{8}$ with the bond lengths and angles in the peptide unit and three torsion angles $\varphi, \psi, \omega$ about the $\mathrm{N}-\mathrm{C}^{\alpha}, \mathrm{C}^{\alpha}-\mathrm{C}^{\prime}$, and $\mathrm{C}^{\prime}-\mathrm{N}$ bonds, respectively. In this study, the bond distances and angles of the peptide unit were fixed at the values proposed by Pauling and Corey, ${ }^{9}$ except the $\mathrm{N}-\mathrm{C}^{\alpha}-\mathrm{C}^{\prime}$ angle; they are $\mathrm{C}^{\alpha}-\mathrm{C}^{\prime}=1.53 \AA, \mathrm{C}^{\prime}-$ $\mathrm{N}=1.32 \AA, \mathrm{N}-\mathrm{C}^{\alpha}=1.47 \AA, \mathrm{N}-\mathrm{C}^{\alpha}-\mathrm{C}^{\prime}=106^{\circ}, \mathrm{C}^{\alpha}-\mathrm{C}^{\prime}-$ $\mathrm{N}=114^{\circ}, \mathrm{C}^{\prime}-\mathrm{N}-\mathrm{C}^{\alpha}=123^{\circ}$ (Table II), and the torsion angle $\omega=180^{\circ}$. For the $\mathrm{N}-\mathrm{C}^{\alpha}-\mathrm{C}^{\prime}$ angle the average value $106^{\circ}$ of those of $\mathrm{L}$-valyl and $\mathrm{L}$ isoleucyl residues in the antiparallel pleated sheet structures in the oligopeptide crystal structures $\left(106^{\circ}\right)$ was adopted..$^{10}$ Substituting these values in Miyazawa's equations (eq 36 and 37 in ref. 8), we obtained

$$
\begin{aligned}
\cos (t / 2)= & -0.796 \sin [(\varphi+\psi) / 2] \\
& +0.047 \sin [(\varphi-\psi) / 2] \\
h \cdot \sin (t / 2)= & 2.892 \cos [(\varphi+\psi) / 2] \\
& -0.695 \cos [(\varphi-\psi) / 2]
\end{aligned}
$$

In the present $\beta$ poly(L-valine) the molecular chain coincided with a crystallographic two-fold screw axis and the period of the $c$-axis corre- sponded to the length of two consecutive valyl residues along the fiber axis. In substituting $t=180^{\circ}$ and $h=c / 2=3.295 \AA$ for the above equations, the conformational parameters were taken as $\varphi=-128.6^{\circ}$ and $\psi=123.1^{\circ}$. The appreciably deviated value $106^{\circ}$ for the $\mathrm{N}-\mathrm{C}^{\alpha}-\mathrm{C}^{\prime}$ angle from the normal tetrahdral angle $109.5^{\circ}$ contracted the peptide chain without energetically destabilizing the geometry of the intermolecular hydrogen bonds.

The torsion angle $\mathrm{N}-\mathrm{C}^{\alpha}-\mathrm{C}^{\beta}-\mathrm{C}^{\gamma_{1}}\left(\chi^{11}\right)$ was evaluated as $180^{\circ}$ by a potential energy calculation with an antiparallel pleated sheet model consisting of three strands of chains containing three residues.

\section{Crystal Structure}

The packing scheme of the molecules thus constructed in the crystal was the same as that in $\beta$ poly(L-alanine). ${ }^{3}$ The crystal structure was statistical, with neighbouring sheets displaced at random $\pm 0.5 a(2.40 \AA)$ in the $a$-axis direction. In other words, each chain site contained half an uppointing chain and half a down-pointing chain, both of the same structure. Thus, the unit cell contained eight structurally equivalent L-valyl residues, each with an occupancy of $1 / 2$. Since a single peptide chain conformation can be defined exactly, the crystal structure were described by the following three parameters:

1. The orientation of the peptide chain plane about the two-fold screw asix $\sigma$, defined as the angle between $(010)$ plane and the normal vector from the chain axis to the $\mathrm{C}^{\alpha}$ atom.

2. The relative translation $\Delta Z^{\mathrm{A}}$ along the $c$-axis direction of the two residues in the asymmetric unit linked by an $\mathrm{NH} \cdots \mathrm{O}$ hydrogen bond;

$$
\text { 1st: } X, Y, Z ; \quad \text { 2nd: } X+4.8 \AA,-Y,-Z+\Delta Z^{\mathrm{A}}
$$

3. The translation of the whole asymmetric unit along the $c$-axis direction $\Delta Z$ (origin at the $\mathrm{C}^{\alpha}$ atom).

\section{Structure Refinement}

The three parameters mentioned above were refined by the $R$-value-map method. The isotropic temperature factor $B$ was fixed at $6.0 \AA^{2}$. Initial values for $\sigma$ and $\Delta Z^{\mathrm{A}}$ were selected so as to make an appropriate interchain hydrogen bond. For calculation of the discrepancy factor $R$, accidental overlapping of reflections were taken into account by 


$$
R=\frac{\sum_{j}\left|K \sqrt{I_{j}^{\circ}}-\sqrt{\sum_{i} m_{i j}\left|F_{i j}^{\mathrm{c}}\right|^{2}}\right|}{\sum_{j} K \sqrt{I_{j}^{\mathrm{o}}}}
$$

where $I_{j}^{0}$ is the Lp corrected intensity of the $j$-th spot of an overlapping reflection, and $m_{i j}$ and $\left|F_{i j}^{\mathfrak{c}}\right|$, the multiplicity factor and the calculated structure amplitude for the $i$-th reflection in the $j$-th spot, respectively, and $K$, a scale factor. The structure with a minimum $R$-value of 0.31 was found to be stereochemically reasonable, where the parameters $\sigma, \Delta Z^{\mathrm{A}}, \Delta Z, B$, and $K$ were $-92^{\circ}, 3.245 \AA, 1.3 \AA$, $6.0 \AA^{2}$, and 0.233 , respectively.

The crystal structure was further refined by the least-squares method with parameters $\sigma, \Delta Z^{\mathrm{A}}, \Delta Z$. After several cycles, convergence was attained. The $R$-value decreased from 0.31 to 0.192 . The final values of the crystal parameters $\sigma, \Delta Z^{\mathrm{A}}, \Delta Z, B$, and $K$ were $-93.36^{\circ}, 3.209 \AA, 1.339 \AA, 6.0 \AA^{2}$, and 0.360 , respectively. The final atomic coordinates are given in Table III. The final model is in good agreement with the observed diffractions. The observed and calculated structure amplitudes are compared in Table IV.

The atomic scattering factors were taken from "International Tables for X-Ray Crystallography,"

Table II. Dimensions of the L-valyl residue used in the model construction

\begin{tabular}{llll}
\hline \multicolumn{3}{r}{ Bond distance $/ \AA$} & \multicolumn{2}{c}{ Bond angle ${ }^{\circ}$} \\
\hline $\mathrm{C}^{\alpha}-\mathrm{C}^{\prime}$ & 1.53 & $\mathrm{~N}-\mathrm{C}^{\alpha}-\mathrm{C}^{\prime}$ & 106 \\
$\mathrm{C}^{\prime}-\mathrm{N}$ & 1.32 & $\mathrm{C}^{\alpha}-\mathrm{C}^{\prime}-\mathrm{N}$ & 114 \\
$\mathrm{~N}-\mathrm{C}^{\alpha}$ & 1.47 & $\mathrm{C}^{\prime}-\mathrm{N}-\mathrm{C}^{\alpha}$ & 123 \\
$\mathrm{C}^{\alpha}-\mathrm{C}^{\beta}$ & 1.53 & $\mathrm{C}^{\alpha}-\mathrm{C}^{\prime}-\mathrm{O}$ & 121 \\
$\mathrm{C}^{\prime}-\mathrm{O}$ & 1.23 & $\mathrm{O}-\mathrm{C}^{\prime}-\mathrm{N}$ & 125 \\
$\mathrm{C}^{\beta}-\mathrm{C}^{\gamma_{1}}$ & 1.53 & $\mathrm{~N}-\mathrm{C}^{\alpha}-\mathrm{C}^{\beta}$ & 110 \\
$\mathrm{C}^{\beta}-\mathrm{C}^{\gamma_{2}}$ & 1.53 & $\mathrm{C}^{\prime}-\mathrm{C}^{\alpha}-\mathrm{C}^{\beta}$ & 110 \\
& & $\mathrm{C}^{\alpha}-\mathrm{C}^{\beta}-\mathrm{C}^{\gamma_{1}}$ & 110 \\
$\mathrm{H}^{\alpha}-\mathrm{C}^{\alpha}$ & 1.00 & $\mathrm{C}^{\alpha}-\mathrm{C}^{\beta}-\mathrm{C}^{\gamma_{2}}$ & 110 \\
$\mathrm{H}^{\beta}-\mathrm{C}^{\beta}$ & 1.00 & $\mathrm{C}^{\gamma_{1}}-\mathrm{C}^{\beta}-\mathrm{C}^{\gamma_{2}}$ & 110 \\
$\mathrm{H}^{\mathrm{N}}-\mathrm{N}$ & 1.00 & & \\
& & $\mathrm{H}^{\alpha}-\mathrm{C}^{\alpha}-\mathrm{N}^{2}$ & 110 \\
& & $\mathrm{H}^{\alpha}-\mathrm{C}^{\alpha}-\mathrm{C}^{\beta}$ & 110 \\
& & $\mathrm{H}^{\alpha}-\mathrm{C}^{\alpha}-\mathrm{C}^{\prime}$ & 110 \\
& & $\mathrm{H}^{\beta}-\mathrm{C}^{\beta}-\mathrm{C}^{\alpha}$ & 110 \\
& & $\mathrm{H}^{\beta}-\mathrm{C}^{\beta}-\mathrm{C}^{\gamma_{1}}$ & 110 \\
& & $\mathrm{H}^{\beta}-\mathrm{C}^{\beta}-\mathrm{C}^{\gamma_{2}}$ & 110 \\
& & $\mathrm{H}^{\mathrm{N}}-\mathrm{N}-\mathrm{C}^{\prime}$ & 123 \\
& & $\mathrm{H}^{\mathrm{N}}-\mathrm{N}-\mathrm{C}^{\alpha}$ & 114 \\
\hline & & &
\end{tabular}

Vol. III, 1974. All calculations were carried out on a FACOM M-200 computer at the Nagoya University Computation Center.

\section{RESULTS AND DISCUSSION}

Figure 1 shows the projections of Fourier syntheses from the three directions along the cell axes. In these syntheses, the observed structure amplitudes $\left|F_{i j}^{o}\right|$, which could not be resolved, were evaluated by the formula

$$
\left|F_{i j}^{\mathrm{o}}\right|=K \sqrt{I_{j}^{\mathrm{o}}} \frac{\left|F_{i j}^{\mathrm{c}}\right|}{\sqrt{\sum_{i} m_{i j}\left|F_{i j}^{\mathrm{c}}\right|^{2}}}
$$

The $a$-axis projection clearly shows the peptide plane and $\mathrm{C}^{\gamma}$ atoms of the side chains; the $c$-axis projection shows the centered core of the main chain and the stack of isopropyl side chains.

In Figure 2 which shows the $a$-axis projection of the crystal structure, two molecules pointing in

\begin{tabular}{|c|c|c|c|}
\hline Atom & $x$ & $y$ & $z$ \\
\hline \multicolumn{4}{|c|}{1 st residue } \\
\hline $\mathrm{C}^{\alpha}$ & -0.0115 & -0.0496 & 0.2032 \\
\hline $\mathbf{H}^{\alpha}$ & -0.2189 & -0.0508 & 0.2171 \\
\hline $\mathrm{C}^{\prime}$ & 0.1163 & -0.0094 & 0.3814 \\
\hline$C^{\beta}$ & 0.1084 & -0.1234 & 0.1941 \\
\hline $\mathrm{H}^{\beta}$ & 0.3159 & -0.1213 & 0.1814 \\
\hline $\mathbf{N}$ & -0.664 & 0.0104 & 0.5197 \\
\hline $\mathrm{H}^{\mathrm{N}}$ & -0.2702 & 0.0002 & 0.5089 \\
\hline $\mathrm{O}$ & 0.3682 & 0.0021 & 0.3891 \\
\hline $\mathrm{C}^{\gamma_{1}}$ & 0.0273 & -0.1640 & 0.3851 \\
\hline $\mathrm{C}^{\gamma_{2}}$ & 0.0001 & -0.1612 & 0.0053 \\
\hline \multicolumn{4}{|c|}{ 2nd residue } \\
\hline$C^{\alpha}$ & 0.9885 & 0.0494 & 0.6902 \\
\hline $\mathrm{H}^{\alpha}$ & 0.7811 & 0.0508 & 0.6763 \\
\hline $\mathrm{C}^{\prime}$ & 1.1163 & 0.0094 & 0.5120 \\
\hline $\mathrm{C}^{\beta}$ & 1.1084 & 0.1234 & 0.6994 \\
\hline $\mathrm{H}^{\beta}$ & 1.3159 & 0.1213 & 0.7121 \\
\hline $\mathrm{N}$ & 0.9336 & -0.0104 & 0.3738 \\
\hline $\mathrm{H}^{\mathrm{N}}$ & 0.7298 & -0.0002 & 0.3846 \\
\hline $\mathrm{O}$ & 1.3682 & -0.0021 & 0.5044 \\
\hline $\mathrm{C}^{\gamma_{1}}$ & 1.0273 & 0.1640 & 0.5083 \\
\hline $\mathrm{C}^{\gamma_{2}}$ & 1.0001 & 0.1612 & 0.8881 \\
\hline
\end{tabular}

Table III. Atomic positional parameters

Symmetry operations: $\mathbf{P} 22_{1} 2_{1} ; x, y, z ; 1 / 2+x, 1 / 2-y$, $-z ;-x,-y, 1 / 2+z ; 1 / 2-x, 1 / 2+y, 1 / 2-z$. The scheme used in $\beta$ poly(L-alanine) by Arnott $^{3}$ was adopted in this study. 
O. Yamashita and T. Ashida

Table IV. Observed and calculated structure amplitudes ${ }^{\mathbf{a}}$

\begin{tabular}{|c|c|c|c|c|c|c|c|c|c|c|c|c|c|c|c|c|c|c|c|}
\hline \multicolumn{5}{|c|}{$l=0$} & \multicolumn{5}{|c|}{$l=1$} & \multicolumn{5}{|c|}{$l=2$} & \multicolumn{5}{|c|}{$l=3$} \\
\hline$h$ & $k$ & $F_{\mathrm{o}}$ & $F_{\mathrm{c}}$ & $F$ & $h$ & $k$ & $F_{\mathrm{o}}$ & $F_{\mathrm{c}}$ & $F$ & $h$ & $k$ & $F_{\mathrm{o}}$ & $F_{\mathrm{c}}$ & $F$ & $h$ & $k$ & $F_{\mathrm{o}}$ & $F_{\mathrm{c}}$ & $F$ \\
\hline \multirow{4}{*}{0} & \multirow{4}{*}{2} & \multirow{4}{*}{159} & \multirow{4}{*}{170} & \multirow{4}{*}{-11} & 0 & 1 & 34 & 25 & 9 & 0 & 2 & 36 & 25 & 11 & \multirow[b]{3}{*}{1} & & \multirow{5}{*}{29} & \multirow[b]{4}{*}{25} & \multirow{5}{*}{4} \\
\hline & & & & & 0 & 2 & 82 & 99 & -17 & 0 & 3 & 36 & 23 & 13 & & & & & \\
\hline & & & & & 0 & 3 & 49 & 25 & 24 & 1 & 0 & & & & & 0 & & & \\
\hline & & & & & 1 & 0 & & & & $\begin{array}{l}0 \\
1\end{array}$ & $\begin{array}{l}4 \\
1\end{array}$ & 71 & 60 & 11 & $\begin{array}{l}0 \\
1\end{array}$ & $\begin{array}{l}4 \\
1\end{array}$ & & & \\
\hline $\begin{array}{l}0 \\
1\end{array}$ & 4 & \multirow[t]{2}{*}{205} & \multirow[t]{2}{*}{195} & \multirow[t]{2}{*}{10} & 0 & 4 & \multirow[t]{2}{*}{111} & \multirow[t]{2}{*}{96} & \multirow[t]{2}{*}{15} & 1 & 2 & & & & 1 & 2 & & & \\
\hline 1 & 1 & & & & $\begin{array}{l}1 \\
1\end{array}$ & $\begin{array}{l}1 \\
2\end{array}$ & & & & $\begin{array}{l}1 \\
0\end{array}$ & $\begin{array}{l}3 \\
5\end{array}$ & \multirow[t]{2}{*}{53} & \multirow[t]{2}{*}{69} & -16 & $\begin{array}{l}1 \\
0\end{array}$ & $\begin{array}{l}3 \\
5\end{array}$ & 29 & 25 & 4 \\
\hline 1 & 3 & 89 & 50 & 39 & $\begin{array}{l}1 \\
0\end{array}$ & $\begin{array}{l}3 \\
5\end{array}$ & 61 & \multirow[t]{2}{*}{76} & -15 & 1 & 4 & & & & 1 & 4 & & & \\
\hline 0 & 6 & & & & & & & & & 0 & 6 & 84 & 85 & -1 & 0 & 6 & 50 & 44 & 6 \\
\hline 1 & 5 & 146 & 167 & -21 & & & & & & 1 & 5 & & & & 1 & 5 & & & \\
\hline 2 & 0 & & & & 2 & 0 & & & & $\begin{array}{l}0 \\
1\end{array}$ & $\begin{array}{l}7 \\
6\end{array}$ & 60 & 55 & 5 & $\begin{array}{l}0 \\
1\end{array}$ & $\begin{array}{l}7 \\
6\end{array}$ & 25 & 29 & -4 \\
\hline 0 & 8 & 128 & 130 & -2 & $\begin{array}{l}0 \\
2\end{array}$ & $\begin{array}{l}8 \\
1\end{array}$ & 81 & 76 & & 2 & 0 & & & & 2 & 0 & & & \\
\hline 1 & 7 & 120 & 150 & -2 & $\begin{array}{l}2 \\
1\end{array}$ & $\begin{array}{l}1 \\
7\end{array}$ & 81 & 10 & -0 & 0 & 8 & & & & 0 & 8 & & & \\
\hline 2 & 2 & & & & & 2 & & & & 2 & 1 & 60 & 43 & 17 & 2 & 1 & 54 & 35 & 19 \\
\hline 1 & 9 & & & & & & & & & 1 & 7 & & & & 1 & 7 & & & \\
\hline 2 & 6 & 91 & 76 & 15 & & & & & & 2 & 2 & & & & 2 & 2 & & & \\
\hline & 10 & & & & & & & & & 2 & 4 & & & & 2 & 4 & & & \\
\hline & & & & & & & & & & $\begin{array}{l}1 \\
0\end{array}$ & $\begin{array}{l}8 \\
9\end{array}$ & 56 & 21 & 35 & 1 & $\begin{array}{l}8 \\
9\end{array}$ & 74 & 49 & 25 \\
\hline & & & & & & & & & & & 5 & & & & 2 & 5 & & & \\
\hline & & & & & & & & & & & & & & & 1 & 9 & & & \\
\hline & & & & & & & & & & & & & & & & 6 & 44 & 12 & 32 \\
\hline & & & & & & & & & & & & & & & & 10 & & & \\
\hline
\end{tabular}

${ }^{\mathrm{a}} F_{\mathrm{o}}=K \sqrt{{I_{j}^{\mathrm{o}}}^{\mathrm{o}}}, F_{\mathrm{c}}=\sqrt{\sum_{i} m_{i}\left|F_{i}{ }^{\mathrm{c}}\right|^{2}}, \Delta F=F_{\mathrm{o}}-F_{\mathrm{c}}$
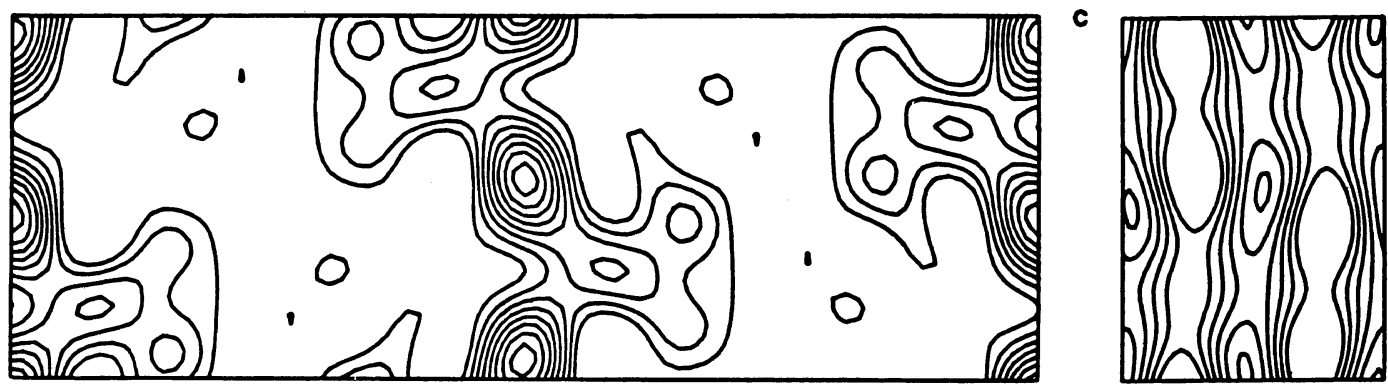

b

0

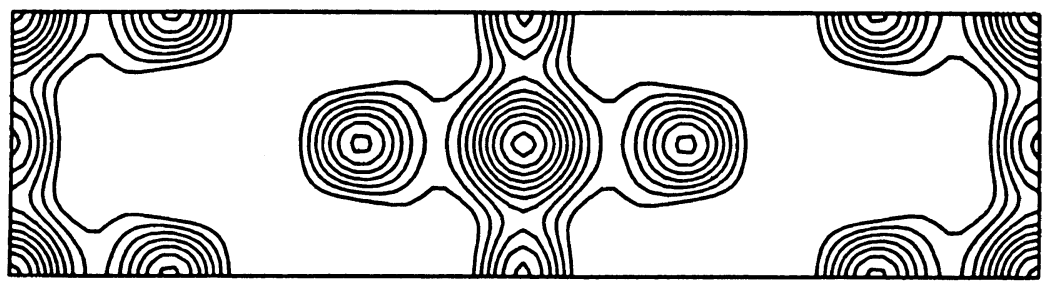

Figure 1. Three Fourier projections along the cell axes. $F(000)$ is not included. Contours are at arbitrary but equal intervals. 


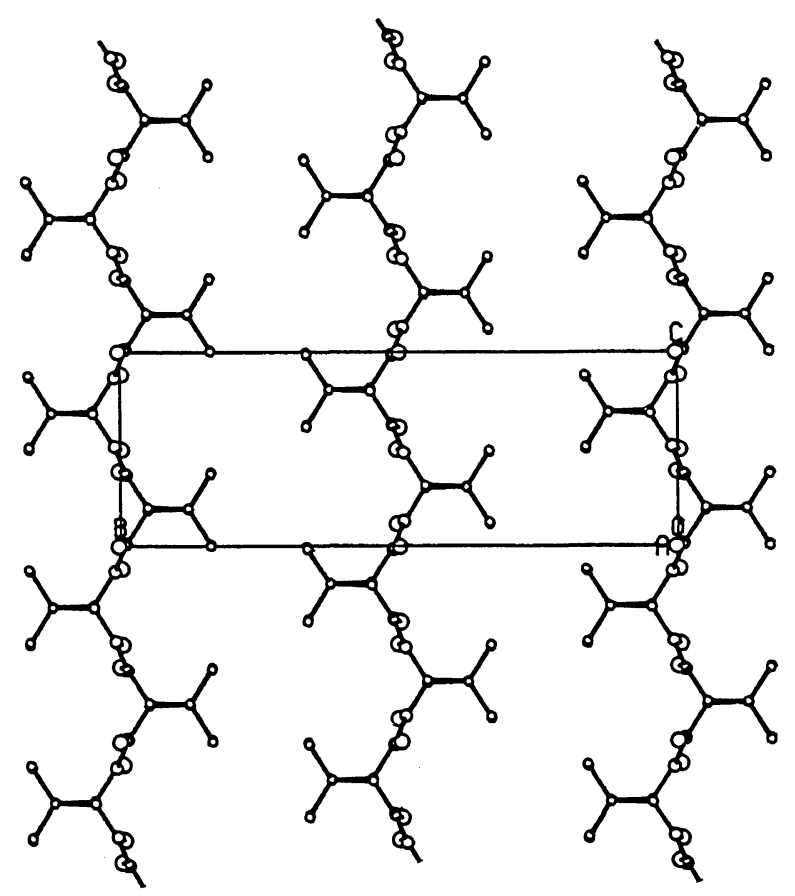

Figure 2. The $a$-axis projection of the crystal structure. Molecular chains are vertical and the direction of hydrogen bonding is normal to the sheet of paper.

opposite direction almost completely overlap with each other. Thus, the side chain of a molecule overlaps with that of the opposite-pointing chain, and the $\mathrm{N}-\mathrm{H}$ of a molecule overlaps with the $\mathrm{C}^{\prime}-\mathrm{O}$ of the chain pointing in the opposite direction. Such a overlapping scheme is shown in Figure 3. The peptide group forms an angle of $29.3^{\circ}$ with the fiber axis, which is called a pleat angle, while that of $\beta$ poly $(\mathrm{L} \text {-alanine })^{3}$ is $20^{\circ}$. A large contraction of the $c$ axis length from the standard value $7.0 \AA$ for Pauling's $\beta$ pleated sheet models ${ }^{11}$ is related to the increase in the pleat angle.

Figure 3 shows the antiparallel pleated sheet of poly(L-valine). The $\mathrm{N} \cdots \mathrm{O}$ and $\mathrm{H} \cdots \mathrm{O}$ distances of 2.73 and $1.74 \AA$, respectively, and the $\mathrm{N}-\mathrm{H} \cdots \mathrm{O}$ angle of $170^{\circ}$ between the chains in the same sheet are in good agreement with the expected hydrogen bonding geometry. Since no condition was introduced that could make an appropriate hydrogen bond during the refinement, this agreement gives credibility to the refined model.

Table V shows the typical intra- and intermolecular distances. There is one kind of intramolecular contact between $\mathrm{C}^{\gamma}$ atoms, which seems to con-
Table V. Typical intra- and intermolecular distances

\begin{tabular}{|c|c|}
\hline Type of interaction & Distance $/ \AA ̊$ \\
\hline \multicolumn{2}{|l|}{ Intramolecular } \\
\hline $\mathrm{C}^{\gamma_{1}}-\mathrm{C}^{\gamma_{2}}$ & 4.09 \\
\hline \multicolumn{2}{|l|}{ Intermolecular } \\
\hline \multicolumn{2}{|l|}{ i) Intrasheet } \\
\hline \multicolumn{2}{|l|}{ ii) Intersheet ${ }^{\mathbf{a}}$} \\
\hline $\mathrm{C}_{\mathrm{u}}^{\gamma_{1}}-\mathrm{C}_{\mathrm{d}}^{\gamma_{1}}$ & 4.16 \\
\hline $\mathrm{C}_{\mathrm{u}}^{\gamma_{2}}-\mathrm{C}_{\mathrm{d}}^{\gamma_{2}}$ & 4.08 \\
\hline $\mathrm{C}_{\mathrm{u}}^{\gamma_{1}}-\mathrm{C}_{\mathrm{u}}^{\gamma_{2}}, \mathbf{C}_{\mathrm{d}}^{\gamma_{1}}-\mathrm{C}_{\mathrm{d}}^{\gamma_{2}}$ & 4.20 \\
\hline $\mathrm{C}_{\mathrm{u}}^{\gamma_{1}}-\mathrm{C}_{\mathrm{u}}^{\gamma_{2}}, \mathrm{C}_{\mathrm{d}}^{\gamma_{1}}-\mathrm{C}_{\mathrm{d}}^{\gamma_{2}}$ & 4.04 \\
\hline
\end{tabular}

${ }^{\mathrm{a}} \mathrm{u}$ and $\mathrm{d}$ stand for up-pointing and down-pointing chains, respectively.

tribute to stabilizing the pleated sheet. The contraction along the fiber axis is attributable to the formation of stable van der Waals contacts among the bulky isopropyl side chains. There are four kinds of intermolecular distances. All of them are normal van der Waals contacts between the pleated 


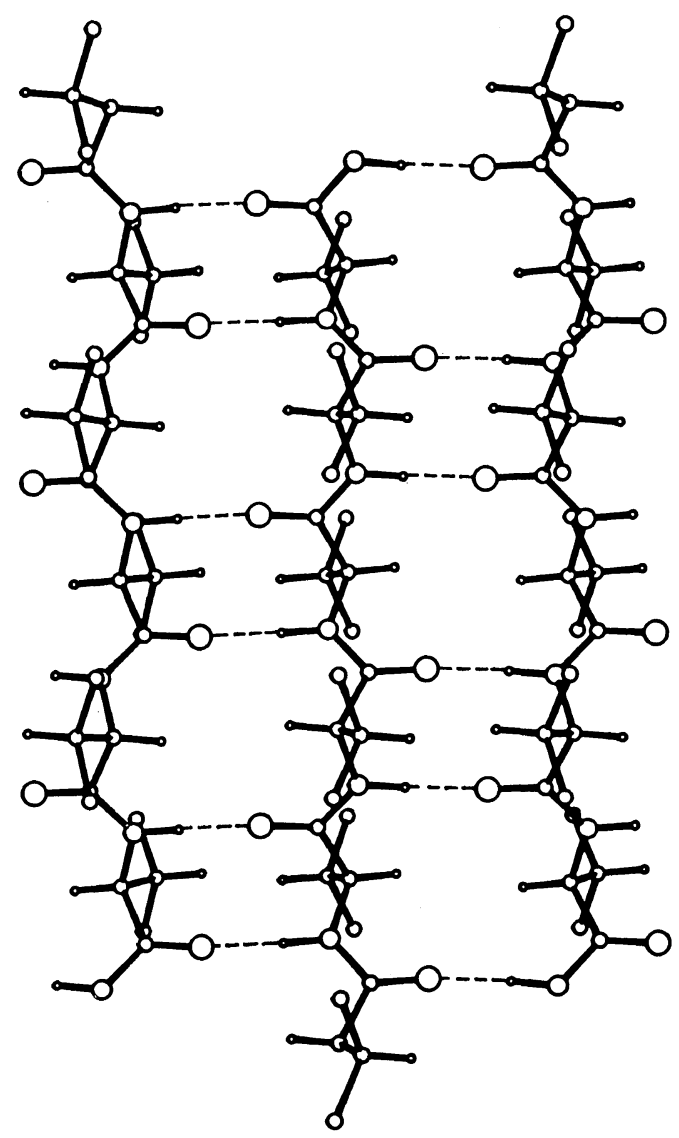

Figure 3. An antiparallel pleated sheet of $\beta$ poly(L-valine) viewed perpendicularly to the sheet. Broken lines represent hydrogen bonds.

sheets. Since the surfaces of the pleated sheet are covered with bulky isopropyl groups, there is no space for the interdigitating to occur in the stacking of the pleated sheets of poly(L-alanine). ${ }^{3}$

Acknowledgement. The authors express their sincere appreciation to Prof. Takuya Yamashita and Dr. Shinsuke Yamashita of Tokushima University for kindly supplying the polypeptide and their helpful comments. The OPTRONICS P-1000 was available through the courtesy of Dr. Noritake Yasuoka of Osaka University.

\section{REFERENCES}

1. O. Yamashita, T. Yamanae, T. Ashida, S. Yamashita, and T. Yamashita, Polym. J., 11, 763
(1979).

2. S. Arnott and A. J. Wonacott, J. Mol. Biol., 21, 371 (1966).

3. S. Arnott, S. D. Dover, and A. Elliott, J. Mol. Biol., 30, 201 (1967).

4. V. Sasisekharan, Acta Crystallogr., 12, 897 (1959).

5. B. Lotz, J. Mol. Biol., 87, 169 (1974).

6. C. H. Bamford, A. Elliott, and W. E. Hanby, "Synthetic Polypeptides," Academic Press, New York, 1956.

7. S. Arnott, Polymer, 6, 478 (1965).

8. T. Miyazawa, J. Polym. Sci., 55, 215 (1961).

9. L. Pauling and R. B. Corey, Proc. Roy. Soc. (London), Ser. B, 141, 10 (1953).

10. T. Ashida, I. Tanaka, and T. Yamane, Int. J. Peptide Protein Res., 17, 322 (1981).

11. L. Pauling and R. B. Corey, Proc. Natl. Acad. Sci. U.S.A., 39, 253 (1953). 